\title{
Study of histopathological findings and clinical presentation in post- menopausal bleeding
}

\author{
Mahalakshmi Aravazhi, V. Breetha*, Rashmi Ajit, S. Sruthi
}

Department of Obstetrics and Gynecology, Kanyakumari Government Medical College and Hospital, Nagercoil, Tamil Nadu, India

Received: 27 January 2022

Revised: 07 February 2022

Accepted: 08 February 2022

*Correspondence:

Dr. V. Breetha,

E-mail: breethamuralidharan@gmail.com

Copyright: (c) the author(s), publisher and licensee Medip Academy. This is an open-access article distributed under the terms of the Creative Commons Attribution Non-Commercial License, which permits unrestricted non-commercial use, distribution, and reproduction in any medium, provided the original work is properly cited.

\section{ABSTRACT}

Background: Aim of the research was to study the clinical significance of post-menopausal bleeding in terms of its risk factors, malignancy incidence, and histopathological evaluation for the cause of the post-menopausal bleed.

Methods: This prospective observational study was conducted in the department of gynecological in Kanyakumari Government Medical College in 100 post-menopausal bleeding per vaginam. Evaluated by history, clinical examination, and investigations like transvaginal sonography, endometrial biopsy, and cervical biopsy for all subjects, the specimens collected will be sent to the pathology dept for examination and reporting. A total of $17 \%$ of patients were observed with an enlarged uterus and $42 \%$ scanty uterine curettings.

Results: The maximum number of patients, $29 \%$, were reported in the age group of 50 to 55 years with an average age of 54.27 years. Para 2 parity (49\%) and body mass index (BMI) value 21 to $30(60 \%)$ were reported maximum in all subjects. Hypertension (17\%) was reported as a major risk factor for endometrial carcinoma. Most of the patients were found with simple hyperplasia without atypia 34 (34\%), followed by atrophic endometritis $32(32 \%)$, and minimum patients have observed complex hyperplasia with atypia 4 (4\%).

Conclusions: The symptom indicating endometrial pathology in post-menopausal women is uterine bleeding. The incidence of a malignant cause of post-menopausal bleeding increases as the time lapse between menopause and the onset of bleeding increases. Atrophic endometritis (atrophic vaginitis) was found to be a major cause of postmenopausal bleeding. Post-menopausal hyperplasia carries a more serious threat of cancer than does premenopausal hyperplasia.

Keywords: Post-menopausal, Histopathological, Bleeding, Malignancy, Clinical significance

\section{INTRODUCTION}

Post-menopausal bleeding (PMB) is one of the most often referred conditions to gynaecological services, owing to the possibility of an underlying endometrial cancer. ${ }^{1} \mathrm{~A}$ woman who does not take hormone replacement treatment (HRT) who bleeds after menopause has a $10 \%$ chance of developing genital cancer and an additional $10 \%$ chance of developing severe pathology. ${ }^{2}$ As a result, any postmenopausal bleeding should be checked, no matter how little or infrequent. Nongenital, genital, uterine, and extrauterine causes are all possibilities. Traumatic bleeding from an atrophic vagina might account for up to $15 \%$ of all post-menopausal bleeding causes. ${ }^{3}$ Endometrial atrophy is the most prevalent endometrial abnormality in women experiencing post-menopausal bleeding, accounting for $60-80 \%$ of cases. Polyps that go unnoticed and untreated might cause recurring or continuous bleeding, resulting in a needless hysterectomy. ${ }^{4,5}$

Endometrial hyperplasia develops in 5-10\% of individuals with post-menopausal uterine haemorrhage. Endometrial 
hyperplasia and cancer are known to be linked to oestrogen. ${ }^{6}$ Obesity, exogenous oestrogen, or an oestrogenic-secreting ovarian tumour are potential sources of excess oestrogen. ${ }^{7}$ Because of prolonged oestrogen stimulation in the absence of progesterone impact, clinically substantial hyperplasia generally develops against a backdrop of proliferative endometrium. ${ }^{8}$ Endometrial hyperplasia is essential not just because it may cause irregular uterine bleeding, but it can also happen before or simultaneously as endometrial cancer. ${ }^{9}$ The most frequent presenting symptom in women diagnosed with endometrial cancer in post-menopausal bleeding. ${ }^{10}$

The benign circumstances will be isolated with proper PMB assessment. Early identification and treatment of malignant lesions and treatment of benign disorders with reassurance can allow a post-menopausal woman to live a healthy life.

Hence the present study was carried out to study the clinical significance of post-menopausal bleeding in terms of its risk factors, the incidence of malignancy and histopathological evaluation for the cause of the postmenopausal bleed.

\section{METHODS}

This prospective observational study was conducted in the department of obstetrics and gynaecology in Kanyakumari Government Medical College in 100 post-menopausal bleeding per vaginam from January 2021 to December 2021.

A total of 100 cases who presented clinically with PMB varying from spotting per vaginum, scanty flow, moderate to profuse bleeding were included.

\section{Inclusion criteria}

All women aged over 45 years with post-menopausal bleeding and had last menstrual period at least 1 year back were included.

\section{Exclusion criteria}

Women with surgical induced, premature, radiationinduced, chemotherapy-induced menopause and women on hormone replacement therapy were excluded from the study.

\section{Procedure}

Women with post-menopausal bleeding attending the outpatient department (OPD) or admitted for evaluation in this prospective study. Written and informed consent from all the patients enrolled in the study. Evaluated by history, clinical examination, and investigations like transvaginal sonography, endometrial biopsy, and cervical biopsy for all subjects, the specimens collected will be sent to the pathology department for examination and reporting.

\section{Ethical committee}

Permission from the institutional ethical committee was taken along with written consent from all volunteers before starting the study. Data were presented as mean, frequency and percentages.

\section{RESULTS}

In the present study, 100 women were enrolled, and their age distribution was recorded. The maximum participants, $38(38 \%)$, were observed in the age group of 55 to 60 years, followed by the age group of 50 to 55 years with 29 (29\%) participants (Table 1). The mean age of participants was reported to be 54.27 years.

Table 1: Age distribution of all participants.

\begin{tabular}{|ll|}
\hline Age in years & No. of cases \\
\hline $\mathbf{5 0 - 5 5}$ & 29 \\
\hline $\mathbf{5 5 - 6 0}$ & 38 \\
\hline $\mathbf{6 0 - 6 5}$ & 24 \\
\hline$>\mathbf{6 5}$ & 9 \\
\hline Total & 100 \\
\hline Mean age & 53.27 \\
\hline
\end{tabular}

The participants were studied based on the parity, it was observed that most of the subjects were para 2 parity 49 (49\%), followed by para 3 parity $25(25 \%)$, and minimum subjects were observed in null para parity (Table 2 ).

Table 2: Distribution of patients based on parity.

\begin{tabular}{|ll|}
\hline Parity & No. of cases \\
\hline Nulli para & 5 \\
\hline Para 1 & 8 \\
\hline Para 2 & 49 \\
\hline Para 3 & 25 \\
\hline Para $>$ 4 & 13 \\
\hline Total & 100 \\
\hline
\end{tabular}

In the present study, the majority, $60(60 \%)$, of the malignancy was observed in patients with BMI less than 30 , followed by 28 (28\%) women with BMI less than 40 . Whereas no patients were observed with blood clots or no viable tissue in the present study (Table 4).

Table 4: Relationship of BMI of post-menopausal bleeding women with histopathology.

\begin{tabular}{|llll|}
\hline Observed cases & BMI & & \\
& $\mathbf{2 1 - 3 0}$ & $\mathbf{3 1 - 3 5}$ & $\mathbf{3 6 - 4 0}$ \\
\hline \multirow{2}{*}{ Percent } & 60 & 28 & 12 \\
\cline { 2 - 4 } & $60 \%$ & $28 \%$ & $12 \%$ \\
\hline
\end{tabular}


The risk factors associated with endometrial cancer were studied in all patients. Hypertension was observed in maximum patients 17 , followed by obesity in 11 patients, and least patients were observed in null gravid 4 (Table 5).

\section{Table 5: Risk factors associated with endometrial} carcinoma.

\begin{tabular}{|ll|}
\hline $\begin{array}{l}\text { Risk factors associated with } \\
\text { endometrial carcinoma }\end{array}$ & No. of cases \\
\hline Hypertension & 17 \\
\hline Diabetes mellitus & 8 \\
\hline Nulli gravida & 4 \\
\hline Obesity & 11 \\
\hline Hypothyroidism & 5 \\
\hline
\end{tabular}

Present evaluated the size of uterine size among all subjects. The majority of the subjects were observed with normal uterine size $60(60 \%)$, whereas $17(17 \%)$ patients were reported with enlarged and $23(23 \%)$ patients with an atrophic uterus were found (Table 6).

Table 6: Observation of uterine size of all subjects.

\begin{tabular}{|ll|}
\hline Uterine size & No. of cases \\
\hline Atrophic & 23 \\
\hline Enlarged uterus & 17 \\
\hline Normal uterus & 60 \\
\hline Total & 100 \\
\hline
\end{tabular}

The type of uterine curettings was studied in all subjects; maximum cases observed were scanty $42(42 \%)$ after that moderate with 32 (32\%) patients (Table 7).

Table 7: Observation of types of uterine curettings in all subjects.

\begin{tabular}{|ll|}
\hline Type of uterine curettings & No. of cases \\
\hline Copius fleshy & 26 \\
\hline Moderate & 32 \\
\hline Scanty & 42 \\
\hline Total & 100 \\
\hline
\end{tabular}

Table 8: Endometrial histopathology in relation to post-menopausal bleeding.

\begin{tabular}{|ll|}
\hline Histopathological examination & No. of cases \\
\hline Atrophic vaginitis & 32 \\
\hline Simple hyperplasia without atypia & 34 \\
\hline Simple hyperplasia with atypia & 14 \\
\hline Complex hyperplasia without atypia & 8 \\
\hline Complex hyperplasia with atypia & 4 \\
\hline Adenocarcinoma & 8 \\
\hline Total & 100 \\
\hline
\end{tabular}

In the present study, histopathological evaluation was correlated with post-menopausal bleeding, most of the patients were found with simple hyperplasia without atypia $34(34 \%)$, followed by atrophic endometritis 32 (32\%), and minimum patients have observed complex hyperplasia with atypia 4 (4\%) (Table 8$)$.

\section{DISCUSSION}

Post-menopausal bleeding is an alarming sign with a high possibility of association with cervical or uterine malignancy. It is one of the commonest symptoms the patient presents with, and hence should be worked upon priority bases to detect abnormalities if any present. ${ }^{1,2}$

The total number of cases studied was 100 , where in the age group of 51 to 55 years had the highest prevalence and the least was noted between the ages of 60 . The study conducted by Wong et al reported the highest patients in the age group of 38-94. ${ }^{11}$ However, Bharani et al observed most patients in the age group of 52 to 65 years, which is similar to our study. ${ }^{12}$ The mean age of the patient in the study we conducted was 54.27 years, whereas it was much lower in the study conducted in the western population.

Further observed that most subjects were para 2 parity 49 (49\%), followed by para 3 parity $25(25 \%)$, and minimum subjects were observed in null para parity. Other studies also reported similar findings. ${ }^{13}$

In the present study, maximum patients were observed in patients with BMI 21 to 30 , followed by BMI of 31 to 35 and minimum malignancy observed in patients with BMI 36 to 40 . These findings in our study are in accordance with earlier studies. ${ }^{3}$

Hypertension was reported as the main risk factor for endometrial cancer $(17 \%)$ in the present study, followed by obesity $(11 \%)$ and diabetes mellitus (8\%). Most patients were observed with the normal uterus, whereas an enlarged uterus was reported in $17 \%$ of subjects. The scanty uterine currenting (42\%) was also highest among subjects. These findings in the present study are similar to earlier reported studies. ${ }^{14}$

The incidences of hyperplasia were found to be $33 \%$ (including simplex and complex) of all hyperplasia observed highest incidences were reported with simple hyperplasia without atypia, $63.63 \%$ and the minimum incidences were for simple hyperplasia with atypia 3 $(9.09 \%)$.

In the present study histopathological evaluation in relation to post-menopausal bleeding, the majority of the patients were reported with simple hyperplasia without atypia (32\%), followed by atrophic endometrium (29\%) and minimum patients were observed complex hyperplasia with atypia (4\%). On the other hand, the studies by Escoffery et al showed a $22 \%$ incidence of hyperplasia, which is slightly lower than the present study. ${ }^{15}$ The higher incidence of endometrial hyperplasia shows that the postmenopausal endometrium in cases of bleeding exhibits an estrogenic effect of varying degrees. 
Atrophic endometrium as the cause of post-menopausal bleeding in the present study was $29 \%$. This was comparable with Pacheco et al who reported $27.7 \%$ atrophic endometrium. ${ }^{16}$ Gredmark et al showed a higher percentage in their series with an incidence of $51.5 \%$ atrophic endometrium. ${ }^{17}$ It is not known why some patients tend to bleed from atrophic endometrium. Anatomical vascular variations or local abnormal haemostatic mechanisms in the uterus have been proposed.

In our study, endometrial adenocarcinoma accounted for $7 \%$ of cases this is comparable with Gredmark et al, $8.4 \%$. However, Pacheco et al had higher incidence of endometrial carcinoma $21.8 \% .^{16,17}$

\section{Limitations}

Small sample size, multiple comparisons without corrections, observational design and risk for confounding were certain limitations.

\section{CONCLUSION}

The only symptom suggesting an endometrial pathology in post-menopausal women is uterine bleeding. Hence, each post-menopausal bleeding requires to be investigated with suspicions. The incidence of a malignant cause of postmenopausal bleeding increases as the time lapse between menopause and the onset of bleeding increases.

Atrophic endometritis (atrophic vaginitis) was a significant cause of post-menopausal bleeding. Postmenopausal hyperplasia carries a stronger threat of cancer than does premenopausal hyperplasia. The atrophic endometrium also played a significant role in PMB in the present study. Therefore the study of endometrial histomorphology in PMB will help appropriate therapeutic management. Among the malignant causes, adenocarcinoma of endometrioid type was most frequent with a lower mean age at presentation.

Although the incidence of post-menopausal bleeding due to malignancy has fallen, it remains sufficiently high to require immediate and thorough investigation.

Funding: No funding sources Conflict of interest: None declared

Ethical approval: The study was approved by the Institutional Ethics Committee

\section{REFERENCES}

1. Hawwa ZM, Nahhas WA, Copenhaver EH. Postmenopausal bleeding. Lahey Clinic Foundation Bulletin. 1970;19(2):61-70.
2. Cheema SZ, Saeed R, Ikram M. Post-menopausal bleeding. Professional Med J. 2008;15(3):328-34.

3. Astrup K, Olivarius NDeF. Frequency of spontaneously occurring post-menopausal bleeding in the general population. Acta Obstetricia et Gynecologica Scandinavica. 2004;83(2):203-7.

4. Brdley LD, Franalcone T, Magen AB. Radiographic Imaging techniques for the diagnosis of abnormal uterine bleeding. Obstet Gynaecol. 2000;27(2):245-77.

5. Parazzini F, Vecchia CLA, Bocciolone L, Franceschi S. The epidemiology of endometrial cancer. Gynecologic Oncology. 1991;41(1):1-16.

6. Norris HJ, Tavassoli FA, Kurman RJ. Endometrial hyperplasia and carcinoma. Diagnostic considerations. Am J Surg Pathol. 1983;7(8):839-47.

7. Alberico S, Conoscenti G, Vegliò P, Bogatti P, Di Bonito L, Mandruzzato G. A clinical and epidemiological study of 245 post-menopausal metrorrhagia patients. Clin Exp Obstet Gynecol. 1989;16(4):113-21.

8. Gordon MD, Ireland K. Pathology of hyperplasia and carcinoma of the endometrium. Semin Oncol. 1994;21(1):64-70.

9. Hunter JE, Tritz DE, Howell MO, DePriest PD, Gallion $\mathrm{HH}$, Andrews SJ, et al. The prognostic and therapeutic implications of cytologic atypia in patients with endometrial hyperplasia. Gynecologic Oncology. 1994;55(1):66-71.

10. Goff BA, Kato D, Schmidt RA, Ek M, Ferry JA, Muntz $\mathrm{HG}$, et al. Uterine papillary serous carcinoma: patterns of metastatic spread. Gynecologic Oncology. 1994;54(3):264-8.

11. F. Wong, KL Luk, AYK Wong, LCH Tang S. Findings in women with postmenopausal bleeding investigated with hysteroscopy. J Obstet Gynaecol. 2001;21(4):3925 .

12. Bharani B, Phatak SR. Feasibility and yield of endometrial biopsy using suction curette device for evaluation of abnormal pre and post-menopausal bleeding. J Obstet Gynecol India. 2008;58(4):322-6.

13. Asim SS, Akhter AZ. Frequency of women with postmenopausal bleeding. ANN Abbasi Shaheed Hospital, Karachi Med Dent Coll. 2004;9(1):506-9.

14. Tyagi R, Isaacs R, Dhar T. Postmenopausal Bleeding: Histopathological Spectrum and Association with Age and Clear Span: Case Series of 328 Cases. J Evol Med Dent Sci. 2014;3(26):7210-21.

15. Escoffery CT, Blake GO, Sargeant LA. Histopathological findings in women with postmenopausal bleeding in Jamaica. West Indian Med J. 2002;51(4):232-5.

16. Pacheco JC, Kempers RD. Etiology of post-menopausal bleeding. Obstet Gynecol. 1968;32(1):40-6.

17. Gredmark T, Kvint S, Havel G, Mattsson LA. Histopathological findings in women with postmenopausal bleeding. $\mathrm{Br} \mathrm{J}$ Obstet Gynaecol. 1995;102(2):133-6.

Cite this article as: Aravazhi M, Breetha V, Ajit R, Sruthi S. Study of histopathological findings and clinical presentation in post-menopausal bleeding. Int J Reprod Contracept Obstet Gynecol 2022;11:735-8. 